Distribution A - Approved for public release; distribution is unlimited.

\title{
Analysis of Polarization Mismatch Loss for Horizontal Linear Feature Detection
}

\author{
Mark A. Govoni, Senior Member, IEEE, Jeffrey S. Spak, Lee R. Moyer, Senior Member, IEEE
}

\begin{abstract}
This research investigates the losses incurred by polarization mismatch, and the impact it has on the detection of horizontal linear features for targets in the ground-plane. We introduce a sequence of steps necessary in mathematically determining the percentage of the horizontal linear feature that is co-polarized with the radar slant plane. Using computer simulation, we numerically evaluate and plot the mismatch loss as a function of polarization and grazing/aspect angles.
\end{abstract}

Index Terms - airborne radar, polarization mismatch loss, horizontal linear feature detection

\section{INTRODUCTION}

$\mathrm{F}$ OR most airborne radar, target detection is possible when the receiver collects target energy in excess of ground - clutter and channel noise. Ground clutter is the predominant impediment to successful detection, and is minimized by varying the grazing angle. Extensive literature exists on backscattering statistics for various terrain types [1, 2]. However, little research exists on the significance of aspect angle and its relationship to polarization mismatch loss. Research has been conducted investigating linear feature detection in synthetic aperture radar imagery [3-12]. Furthermore, general research exploring the phenomena encountered by communications systems when varying polarizations has also been conducted [13-18].

Polarization mismatch loss occurs because most imaging geometries have limited aspect to target. This causes the antenna's slant plane to align poorly with the target linear feature, and results in a portion of the transmit signal reflecting at an orthogonal polarization. The polarization mismatch loss is in addition to the (two-way) antenna loss that occurs at target angles off the antenna boresight. By analyzing the polarization mismatch as a function of both aspect and grazing angles, we can numerically evaluate the expected loss as they relate to horizontal linear feature detection.

In Section II, we establish the basis for our vector model and define the vectors used in the subsequent sections. In Section III, we focus on the polarization mismatch resulting when target horizontal linear feature(s) are poorly aligned with the radar line-of-sight vector and derive the polarization mismatch equations as a function of the slantplane normal and linear feature vector. We then numerically evaluate the expected loss and plot the results. In Section IV, conclusions are made and future efforts are mentioned.

\section{VECTOR MODEL}

We first introduce some assumptions about the target. (1) We assume the target lies on an ideal ground-plane free of surface irregularities. (2) We assume the target surface is symmetric about its central axis and that linear features are much greater than the radar wavelength. In this analysis, we use a North, East, Down (NED) coordinate system where the antenna is located at the origin $(0,0,0)$. In our model, the target is located at a point in the ground plane $\left(u_{x}, u_{y}, u_{h}\right)$. Therefore, the radar line-of-sight (LOS) vector can be represented by $\mathbf{u}_{\mathrm{LOS}}=\left[u_{x}, u_{y}, u_{h}\right]$ and similarly, $\mathbf{u}_{\mathrm{F}_{-} \mathrm{H}}=\left[-\sin \psi_{a}, \cos \psi_{a}, 0\right]$ represents the horizontal linear feature where $\psi_{a}$ is the aspect angle. The horizontallypolarized antenna vector is represented by $\mathbf{u}_{\mathrm{A}_{-} \mathrm{H}}=[0,1,0]$ and its vertical counterpart is $\mathbf{u}_{\mathrm{A}_{-} \mathrm{V}}=[\sin \theta$, 0 , cos $\theta]$ where $\theta$ is the antenna tilt angle.

Manuscript submitted on January xx, 2012

M. A. Govoni is a senior research scientist for the US Army CERDEC I2WD, Aberdeen Proving Ground, MD, 21005 (email: mark.govoni@mi.army.mil).

J. Spak is a radar technologist for the US Army CERDEC I2WD, Aberdeen Proving Ground, MD, 21005 (email: jeffrey.spak@mi.army.mil).

L. Moyer is a Vice President of Technology Service Corporation and serves as a radar Subject Matter Expert to the US Army (email: lee.moyer@tsc.com) 


\section{Report Documentation Page}

Form Approved

OMB No. 0704-0188

Public reporting burden for the collection of information is estimated to average 1 hour per response, including the time for reviewing instructions, searching existing data sources, gathering and maintaining the data needed, and completing and reviewing the collection of information. Send comments regarding this burden estimate or any other aspect of this collection of information,

including suggestions for reducing this burden, to Washington Headquarters Services, Directorate for Information Operations and Reports, 1215 Jefferson Davis Highway, Suite 1204, Arlington

VA 22202-4302. Respondents should be aware that notwithstanding any other provision of law, no person shall be subject to a penalty for failing to comply with a collection of information if it

does not display a currently valid OMB control number.

\begin{tabular}{|c|c|c|}
\hline $\begin{array}{l}\text { 1. REPORT DATE } \\
\mathbf{1 2} \text { JUN } \mathbf{2 0 1 2}\end{array}$ & $\begin{array}{l}\text { 2. REPORT TYPE } \\
\text { Technical Report }\end{array}$ & $\begin{array}{l}\text { 3. DATES COVERED } \\
\mathbf{1 2 - 0 1 - 2 0 1 2} \text { to } \mathbf{1 2 - 0 6 - 2 0 1 2}\end{array}$ \\
\hline \multirow{3}{*}{\multicolumn{2}{|c|}{$\begin{array}{l}\text { A. TITLE AND SUBTITLE } \\
\text { Analysis of Polarization Mismatch Loss for Horizontal Linear Feature } \\
\text { Detection }\end{array}$}} & 5a. CONTRACT NUMBER \\
\hline & & 5b. GRANT NUMBER \\
\hline & & 5c. PROGRAM ELEMENT NUMBER \\
\hline \multirow{3}{*}{\multicolumn{2}{|c|}{$\begin{array}{l}\text { 6. AUTHOR(S) } \\
\text { Mark Govoni; Jeff Spak; Lee Moyer }\end{array}$}} & 5d. PROJECT NUMBER \\
\hline & & 5e. TASK NUMBER \\
\hline & & 5f. WORK UNIT NUMBER \\
\hline \multicolumn{2}{|c|}{$\begin{array}{l}\text { 7. PERFORMING ORGANIZATION NAME(S) AND ADDRESS(ES) } \\
\text { US Army CERDEC I2WD,Building 6003,Aberdeen Proving } \\
\text { Ground,MD,21009 }\end{array}$} & $\begin{array}{l}\text { 8. PERFORMING ORGANIZATION } \\
\text { REPORT NUMBER } \\
\text { RDER-IW-RI R1 }\end{array}$ \\
\hline \multirow{2}{*}{\multicolumn{2}{|c|}{ 9. SPONSORING/MONITORING AGENCY NAME(S) AND ADDRESS(ES) }} & 10. SPONSOR/MONITOR'S ACRONYM(S) \\
\hline & & $\begin{array}{l}\text { 11. SPONSOR/MONITOR'S REPORT } \\
\text { NUMBER(S) }\end{array}$ \\
\hline
\end{tabular}

12. DISTRIBUTION/AVAILABILITY STATEMENT

Approved for public release; distribution unlimited

13. SUPPLEMENTARY NOTES

14. ABSTRACT

This research investigates the losses incurred by polarization mismatch, and the impact it has on the detection of horizontal linear features for targets in the ground-plane. We introduce a sequence of steps necessary in mathematically determining the percentage of the horizontal linear feature that is co-polarized with the radar slant plane. Using computer simulation, we numerically evaluate and plot the mismatch loss as a function of polarization and grazing/aspect angles.

15. SUBJECT TERMS

airborne radar, polarization mismatch loss, horizontal linear feature detection

\begin{tabular}{|c|c|c|c|c|c|}
\hline 16. SECURITY CLASSIFICATION OF: & $\begin{array}{c}\text { 17. LIMITATION OF } \\
\text { ABSTRACT }\end{array}$ & $\begin{array}{c}\text { 18. NUMBER } \\
\text { OF PAGES }\end{array}$ & $\begin{array}{c}\text { 19a. NAME OF } \\
\text { RESPONSIBLE PERSON }\end{array}$ \\
\cline { 1 - 2 } $\begin{array}{c}\text { a. REPORT } \\
\text { unclassified }\end{array}$ & $\begin{array}{c}\text { b. ABSTRACT } \\
\text { unclassified }\end{array}$ & $\begin{array}{c}\text { c. THIS PAGE } \\
\text { unclassified }\end{array}$ & $\mathbf{3}$ & $\mathbf{7}$ & \\
\end{tabular}


The following describes the basic components of the vector model:

- $\quad \psi_{g}$ is the grazing angle for the radar LOS vector

- $\quad \psi_{a}$ is the aspect angle for the radar LOS to the target where 0 -deg aspect is considered broadside

- $\quad x$ is the ground-plane projection for the radar LOS vector

- $y$ is orthogonal to $x$ and serves as reference for aspect angle

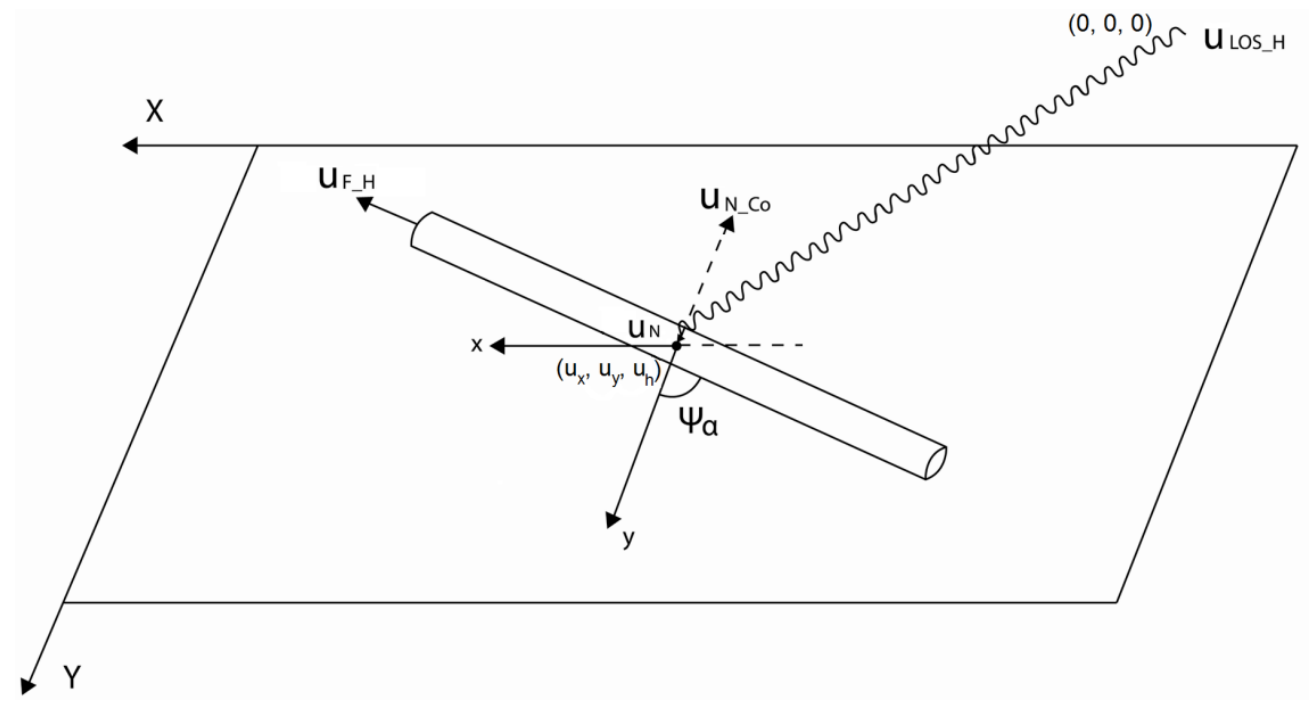

(a)

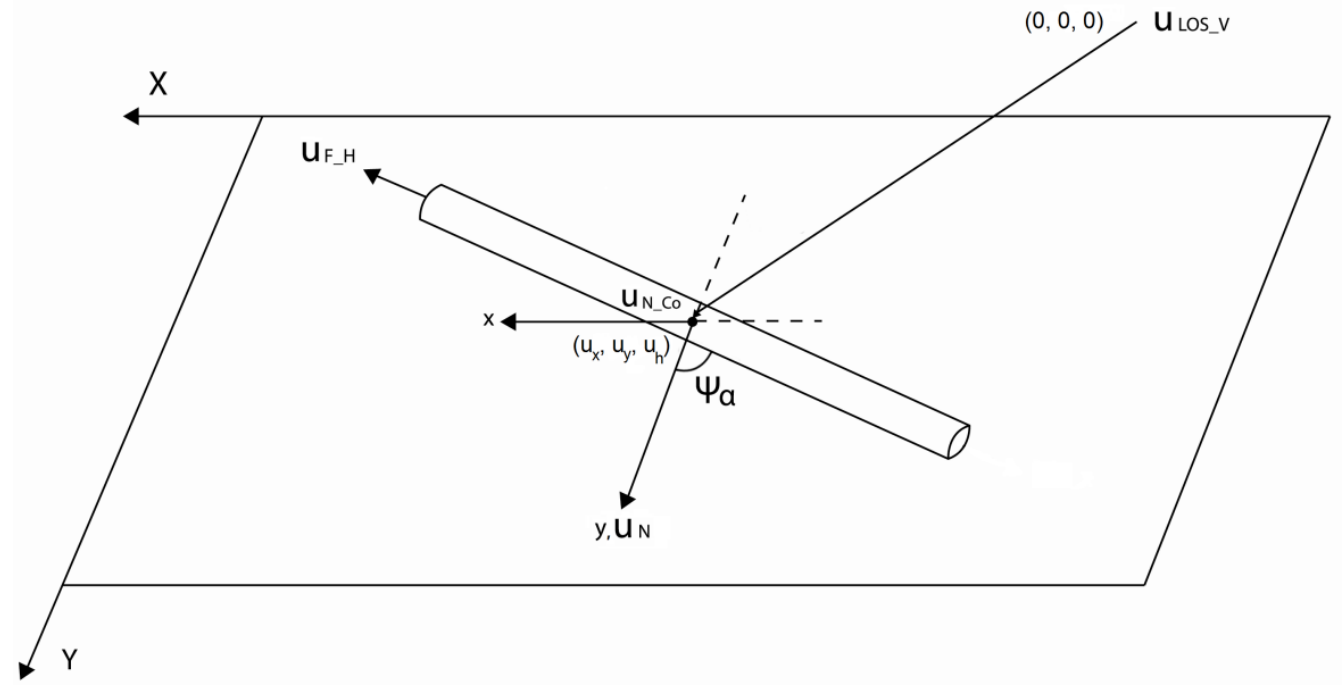

(b)

Figure 1. Target geometry relative to radar aspect angle $\left(\psi_{a}\right)$ : (a) horizontally-polarized line-of-sight vector $\left(\mathbf{u}_{\text {LOS_H }}\right)$, (b) vertically-polarized line-of-sight vector $\left(\mathbf{u}_{\mathrm{LOS} \_\mathrm{V}}\right)$. Both are projected into the ground-plane bounded by the $\mathrm{XY}$-axes. The horizontal linear feature vector $\left(\mathbf{u}_{\mathrm{F}_{-}}\right)$, the slant plane normal $\left(\mathbf{u}_{\mathrm{N}}\right)$, and the co-polarization vector $\left(\mathbf{u}_{N_{-} \mathrm{Co}}\right)$ are included.

III. POLARIZATION MISMATCH LOSS 


\section{A. Horizontally-polarized slant plane}

The horizontally-polarized component of the target linear feature is determined in the following manner:

1. The cross-product of $\mathbf{u}_{\mathrm{A} \_\mathrm{H}}$ and $\mathbf{u}_{\mathrm{LOS}}$ is taken to form $\mathbf{u}_{\mathrm{N}}$, which is orthogonal to the horizontally-polarized slant plane and is formed at the center of the target

2. The cross-product of $\mathbf{u}_{\mathrm{LOS}}$ and $\mathbf{u}_{\mathrm{N}}$ is taken to form $\mathbf{u}_{\mathrm{N} \_ \text {Co }}$, which is orthogonal to both vectors

3. The dot-product of $\mathbf{u}_{\mathrm{N}_{-} \mathrm{Co}}$ and $\mathbf{u}_{\mathrm{F}_{-} \mathrm{H}}$ quantifies the amount of radar return from the linear feature that is contained in the horizontally-polarized slant plane

The unit vector ( $\hat{\mathbf{u}})$ orthogonal to the horizontally-polarized slant plane is derived from the cross-product of the horizontally-polarized antenna vector and the radar LOS vector,

$$
\hat{\mathbf{u}}_{\mathrm{N}}=\mathbf{u}_{\mathrm{A} \_\mathrm{H}} \mathrm{X} \mathbf{u}_{\mathrm{LOS}} /\left\|\mathbf{u}_{\mathrm{A} \_\mathrm{H}} \mathrm{X} \mathbf{u}_{\mathrm{LOS}}\right\|,
$$

where $\|\bullet\|$ represents the vector norm. The cross-product is first calculated as

$$
\begin{gathered}
\hat{\mathbf{u}}_{\mathrm{N}}=\left|\begin{array}{ccc}
i & j & k \\
u_{A_{-} H}(1) & u_{A_{-} H}(2) & u_{A_{-} H}(3) \\
u_{L O S}(1) & u_{L O S}(2) & u_{L O S}(3)
\end{array}\right|, \\
=\left|\begin{array}{ccc}
i & j & k \\
0 & 1 & 0 \\
u_{x} & u_{y} & u_{h}
\end{array}\right|, \\
=\operatorname{det}\left|\begin{array}{cc}
1 & 0 \\
u_{y} & u_{h}
\end{array}\right| i+\operatorname{det}\left|\begin{array}{cc}
0 & 0 \\
u_{h} & u_{x}
\end{array}\right| j+\operatorname{det}\left|\begin{array}{cc}
0 & 1 \\
u_{x} & u_{y}
\end{array}\right| k,
\end{gathered}
$$

where the det $|\bullet|$ is the determinant. The unit vector can then be represented as

$$
\hat{\mathbf{u}}_{\mathrm{N}}=\left(u_{h} i-u_{x} k\right) /\left(u_{x}^{2}+u_{h}^{2}\right)^{1 / 2} .
$$

The cross-product of $\mathbf{u}_{\mathrm{LOS}}$ and $\mathbf{u}_{\mathrm{N}}$ produces the co-polarization unit vector,

$$
\begin{aligned}
\hat{\mathbf{u}}_{\mathrm{N}_{-} \mathrm{Co}} & \left.=\mathbf{u}_{\mathrm{LOS}} \times \hat{\mathbf{u}}_{\mathrm{N}}=\left(-u_{x} u_{y} i+\left(u_{x}^{2}+u_{h}^{2}\right) j-u_{h} u_{y} k\right) /\left[\left(u_{x} u_{y}\right)^{2}+\left(u_{x}{ }^{2}+u_{h}^{2}\right)^{2}+\left(u_{h} u_{y}\right)\right)^{2}\right]^{1 / 2}, \\
& \left.=\left(-u_{x}^{2} \tan \psi_{a} i+\left(u_{x}{ }^{2}+u_{h}^{2}\right) j-u_{h} u_{x} \tan \psi_{a} k\right) /\left[\left(u_{x}{ }^{2} \tan \psi_{a}\right)^{2}+\left(u_{x}{ }^{2}+u_{h}{ }^{2}\right)^{2}+\left(u_{h} u_{x} \tan \psi_{a}\right)\right)^{2}\right]^{1 / 2} .
\end{aligned}
$$

Thus, if the dot-product of $\mathbf{u}_{\mathrm{N}_{-} \mathrm{Co}}$ and $\mathbf{u}_{\mathrm{F}_{-} \mathrm{H}}$ is one then the return from the linear feature will be entirely contained within the horizontally-polarized slant plane. This case results when $\psi_{a}=0$ degrees. Conversely, if the dot-product is zero then none of the return will be contained within the horizontally-polarized slant plane. This is illustrated in Figure 1(a) where the vector orthogonal to the horizontally-polarized slant plane is shown coming out of the page, while an arbitrary aspect angle adds perspective to the model. As evidenced, the cross-product between the radar LOS vector and the orthogonal vector results in a co-polarization vector that is orthogonal to the radar LOS vector.

To verify this, the dot-product magnitude of the co-polarization and linear feature unit vectors is calculated as,

$$
\begin{aligned}
\mathrm{N}_{\mathrm{C}{ }_{-} \mathrm{H}} & =\left|\hat{\mathbf{u}}_{\mathrm{N} \_\mathrm{Co}} \cdot \hat{\mathbf{u}}_{\mathrm{F}_{-} \mathrm{H}}\right|, \\
& =\left|\left(u_{x}{ }^{2} \sin \psi_{a} \tan \psi_{a}+\left(u_{x}{ }^{2}+u_{h}{ }^{2}\right) \cos \psi_{a}\right) /\left[\left(u_{x}{ }^{2} \tan \psi_{a}\right)^{2}+\left(u_{x}{ }^{2}+u_{h}{ }^{2}\right)^{2}+\left(u_{h} u_{x} \tan \psi_{a}\right)^{2}\right]^{1 / 2}\right|,
\end{aligned}
$$




$$
\begin{aligned}
& \left.=\mid\left[\left(u_{x}{ }^{2} / \cos \psi_{a}\right)+u_{h}{ }^{2} \cos \psi_{a}\right] /\left[\left(u_{x}{ }^{2} \tan \psi_{a}\right)^{2}+\left(u_{x}{ }^{2}+u_{h}{ }^{2}\right)^{2}+\left(u_{h} u_{x} \tan \psi_{a}\right)\right)^{2}\right]^{1 / 2} \mid, \\
& =\left|\left[u_{x}{ }^{2}+u_{h}{ }^{2}\left(\cos \psi_{a}\right)^{2}\right] /\left[u_{x}{ }^{4}+\left(2 u_{x}{ }^{2} u_{h}{ }^{2}\right)\left(\cos \psi_{a}\right)^{2}+u_{h}{ }^{4}\left(\cos \psi_{a}\right)^{2}+u_{h}{ }^{2} u_{x}{ }^{2}\left(\sin \psi_{a}\right)^{2}\right]^{1 / 2}\right|, \\
& =\left|\left[u_{x}{ }^{2}+u_{h}{ }^{2}\left(\cos \psi_{a}\right)^{2}\right] /\left[u_{x}{ }^{4}+u_{x}{ }^{2} u_{h}{ }^{2}\left(1+\left(\cos \psi_{a}\right)^{2}\right)+u_{h}{ }^{4}\left(\cos \psi_{a}\right)^{2}\right]^{1 / 2}\right|, \\
& =\left|\left[1+\left(u_{h} / u_{x}\right)^{2}\left(\cos \psi_{a}\right)^{2}\right] /\left[1+\left(u_{h} / u_{x}\right)^{2}\left(1+\left(\cos \psi_{a}\right)^{2}\right)+\left(u_{h} / u_{x}\right)^{4}\left(\cos \psi_{a}\right)^{2}\right]^{1 / 2}\right| .
\end{aligned}
$$

Sample calculations verified that $\left(\mathrm{N}_{\mathrm{X}_{\_} \mathrm{H}}\right)^{2}+\left(\mathrm{N}_{\mathrm{C}{ }_{-} \mathrm{H}}\right)^{2}=1$ where $\mathrm{N}_{\mathrm{X}_{\_} \mathrm{H}}=\left|\hat{\mathbf{u}}_{\mathrm{N}} \cdot \hat{\mathbf{u}}_{\mathrm{F}_{-} \mathrm{H}}\right|=\left|-\sin \psi_{a} /\left[\left(1+u_{x} / u_{h}\right)^{2}\right]^{1 / 2}\right|$. From here, the polarization mismatch loss in the horizontal plane is calculated as,

$$
\mathrm{L}_{\mathrm{H}}=10 \log _{10}\left(\mathrm{~N}_{\mathrm{Co} \_\mathrm{H}}\right)^{2} .
$$

Figure 2 plots the polarization mismatch loss for horizontal polarization when various aspect and grazing angles are considered. In our analysis, the altitude was held constant at 25,000 ft (7.6 km). It can be seen from the figure that the loss increases proportional with increases in both aspect and grazing angles. Therefore, if one wanted to minimize the polarization mismatch loss for a horizontally-polarized radar slant plane, they would need small aspect angles and shallow grazing angles. However, it's important to keep in mind that certain radar applications, such as foliage penetration, require steeper grazing angles in order to circumvent foliage-induced attenuation [1, 2]. So, while polarization mismatch can be significant for different combinations of aspect and grazing angles, one must also weigh the adverse effects of operating at shallower grazing angles when employing a horizontally-polarized slant plane.

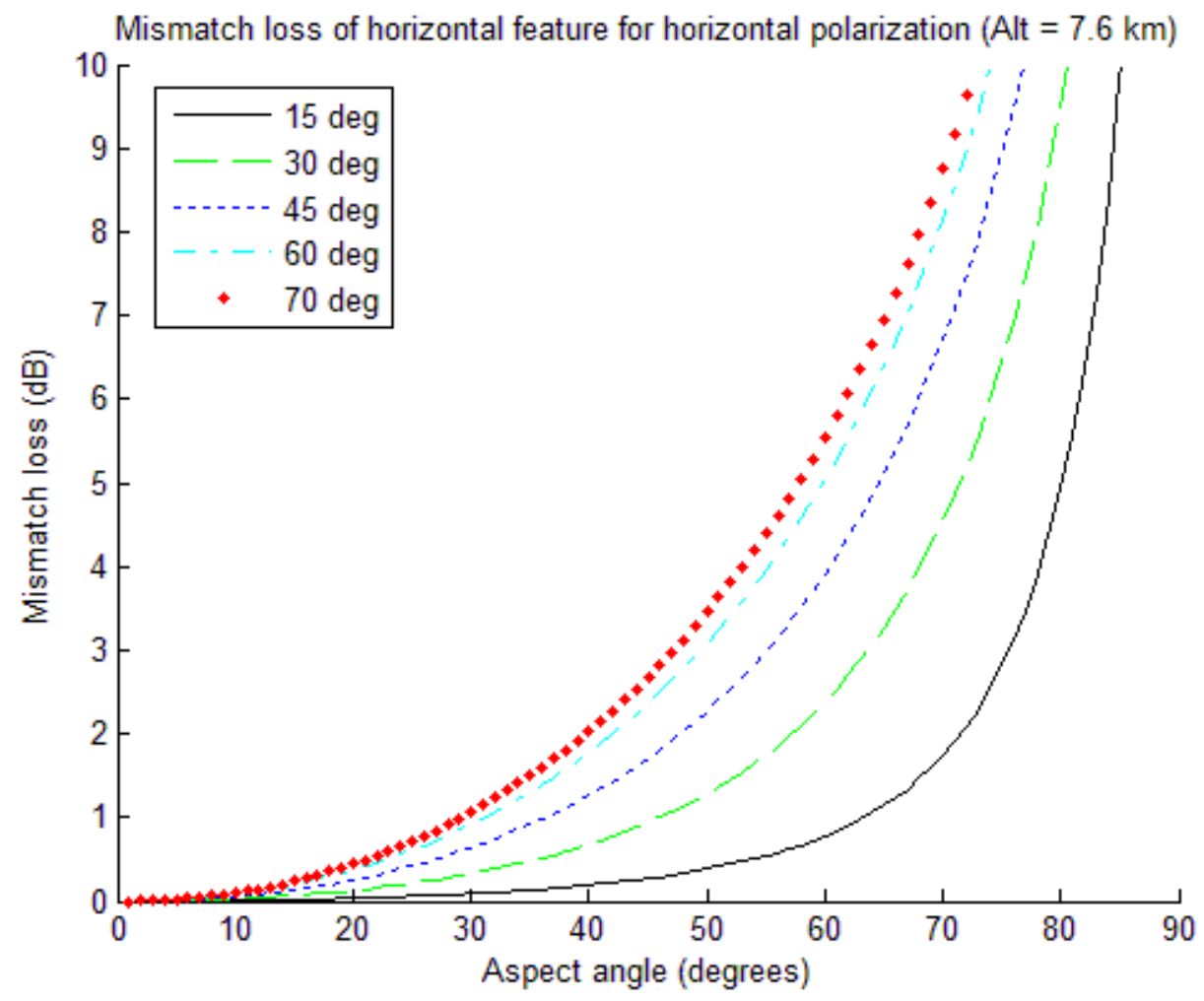

Figure 2. The polarization mismatch loss for the horizontally-polarized slant plane. A fixed altitude of 25,000 ft $(7.6 \mathrm{~km})$ was chosen while grazing angles were varied from shallow to steep (15 - $70 \mathrm{deg})$. 


\section{B. Vertically-polarized slant plane}

We now investigate the response of the horizontal linear feature when a vertically-polarized radar slant plane is considered. The vertically-polarized component of the target linear feature is determined in a similar manner to that of the horizontally-polarized case. Those steps are repeated here for convenience:

1. The cross-product of $\mathbf{u}_{\mathrm{A}_{-V} \mathrm{~V}}$ and $\mathbf{u}_{\mathrm{LOS}}$ is taken to form $\mathbf{u}_{\mathrm{N}}$, which is orthogonal to the vertically-polarized slant plane and is formed at the center of the target

2. The dot-product of $\mathbf{u}_{\mathrm{N}}$ and $\mathbf{u}_{\mathrm{F}_{-} \mathrm{H}}$ quantifies the amount of radar return from the linear feature that is not contained in the horizontally-polarized slant plane

The unit vector orthogonal to the vertically-polarized slant plane is derived from the cross-product of the vertically-polarized antenna vector and the radar LOS vector,

$$
\begin{aligned}
& \hat{\mathbf{u}}_{\mathrm{N}}=\mathbf{u}_{\mathrm{A}_{-} \mathrm{V}} \times \mathbf{u}_{\mathrm{LOS}}=\left[u_{y} \cos \theta i-\left(u_{h} \sin \theta+u_{x} \cos \theta\right) j+u_{y} \sin \theta k\right] /\left[u_{y}{ }^{2}+\left(u_{h} \sin \theta+u_{x} \cos \theta\right)^{2}\right]^{1 / 2}, \\
= & {\left[u_{x} \tan \psi_{a} \cos \theta i-\left(u_{h} \sin \theta+u_{x} \cos \theta\right) j+u_{x} \tan \psi_{a} \sin \theta k\right] /\left[\left(u_{x} \tan \psi_{a}\right)^{2}+\left(u_{h} \sin \theta+u_{x} \cos \theta\right)^{2}\right]^{1 / 2} . }
\end{aligned}
$$

Thus, if the dot-product of $\mathbf{u}_{\mathrm{N}}$ and $\mathbf{u}_{\mathrm{F}_{-} \mathrm{H}}$ is zero then the return from the linear feature will be entirely contained within the vertically-polarized slant plane. This case results when $\psi_{a}=90$ degrees. Conversely, if the dot-product is one then none of the return will be contained within the vertically-polarized slant plane. This is illustrated in Figure 1(b) where the vector orthogonal to the vertically-polarized slant plane is parallel to the Y-axis in the ground plane, while an arbitrary aspect angle adds perspective to the model. As evidenced, the cross-product between the radar LOS vector and the orthogonal vector results in a co-polarization vector that is orthogonal to the radar LOS vector.

To verify this, the dot-product magnitude of the vector normal to the vertically-polarized slant plane and linear feature unit vectors is calculated as,

$$
\begin{gathered}
\mathrm{N}_{\mathrm{X}_{-} \mathrm{V}}=\left|\hat{\mathbf{u}}_{\mathrm{N}} \cdot \hat{\mathbf{u}}_{\mathrm{F}_{-} \mathrm{H}}\right|, \\
=\left|\left[-u_{x} \tan \psi_{a} \cos \theta \sin \psi_{a}-\left(u_{h} \sin \theta+u_{x} \cos \theta\right) \cos \psi_{a}\right] /\left[\left(u_{x} \tan \psi_{a}\right)^{2}+\left(u_{h} \sin \theta+u_{x} \cos \theta\right)^{2}\right]^{1 / 2}\right|, \\
=\left|\left[\left(-u_{x} \cos \theta / \cos \psi_{a}\right)-u_{h} \sin \theta \cos \psi_{a}\right] /\left[\left(u_{x} \tan \psi_{a}\right)^{2}+\left(u_{h} \sin \theta+u_{x} \cos \theta\right)^{2}\right]^{1 / 2}\right|, \\
=\left|\left[\left(-u_{x} / u_{h}\right) \cos \theta-\sin \theta\left(\cos \psi_{a}\right)^{2}\right] /\left[\left(u_{x} / u_{h}\right)^{2}\left(\sin \psi_{a}\right)^{2}+\left(\sin \theta+\left(u_{x} / u_{h}\right) \cos \theta\right)^{2}\left(\cos \psi_{a}\right)^{2}\right]^{1 / 2}\right| .
\end{gathered}
$$

Sample calculations verified that $\left(\mathrm{N}_{\mathrm{X}_{-} \mathrm{V}}\right)^{2}+\left(\mathrm{N}_{\mathrm{Co}_{-} \mathrm{V}}\right)^{2}=1$ where $\mathrm{N}_{\mathrm{Co}_{-} \mathrm{V}}=\left|\hat{\mathbf{u}}_{\mathrm{N}_{-} \mathrm{Co}} \cdot \hat{\mathbf{u}}_{\mathrm{F}_{-} \mathrm{H}}\right|=\mid\left[-u_{x} u_{h} \sin \psi_{a}+u_{y} u_{h} \cos \psi_{a}\right] /$ $\left[\left(u_{x} u_{h} \sin \psi_{a}\right)^{2}+\left(u_{y} u_{h} \cos \psi_{a}\right)^{2}\right]^{1 / 2}$. From here, the polarization mismatch loss in the vertical plane is calculated as,

$$
\mathrm{L}_{\mathrm{V}}=10 \log _{10}\left(1-\mathrm{N}_{\mathrm{X}_{-} \mathrm{V}}\right)^{2} .
$$

Figure 3 plots the polarization mismatch loss for vertical polarization when various aspect and grazing angles are considered. In our analysis, the altitude was held constant at 25,000 ft $(7.6 \mathrm{~km})$ and an antenna tilt angle of 35 degrees was assumed. Both parameters are fairly typical for airborne radar. It can be seen from the figure that the loss increases proportional with decreases in both aspect and grazing angles. Therefore, if one wanted to minimize the polarization mismatch loss for a vertically-polarized radar slant plane, they would essentially do the opposite of what is required in the horizontally-polarized case. Therefore, steeper grazing angles and large aspect angles would yield the best results for the vertically-polarized case. It's important to keep in mind that certain radar applications require shallower grazing angles in order to circumvent clutter backscatter [1, 2]. So, while polarization mismatch can be significant for different combinations of aspect and grazing angles, one must also weigh the adverse effects of operating at steeper grazing angles when employing a vertically-polarized slant plane. 


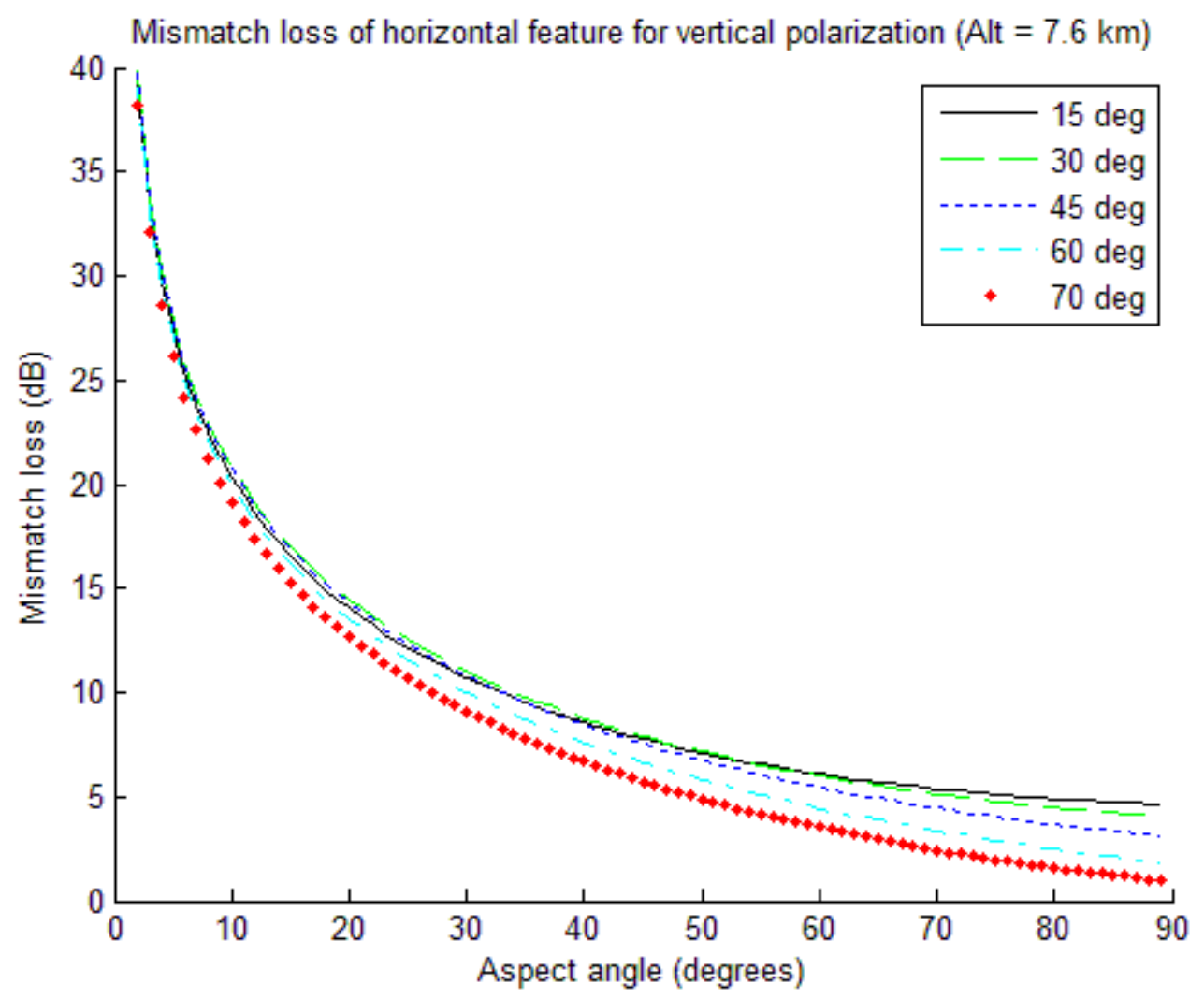

Figure 3. The polarization mismatch loss for the vertically-polarized slant plane. A fixed altitude of 25,000 ft (7.6 $\mathrm{km}$ ) was chosen while grazing angles were varied from shallow to steep (15 - $70 \mathrm{deg})$. The antenna tilt angle $(\theta)$ is 35 degrees.

\section{CONCLUSIONS}

In this paper, a preliminary analysis of the polarization mismatch loss for horizontal linear features was presented. It was shown that when considering a horizontally-polarized slant plane, shallower grazing angles and smaller aspect angles to target would minimize polarization mismatch loss. Conversely, when considering a verticallypolarized slant plane, we observed steeper grazing angles and larger aspect angles minimize polarization mismatch loss. Observations were made on how one might be inclined to compensate for the polarization mismatch loss without considering the severity of foliage-induced attenuation or terrain backscatter. It's important to remember that while polarization mismatch can be significant for different combinations of aspect and grazing angles, one must also weigh the adverse effects of using certain grazing angles for a given terrain-type.

Future work will incorporate measured data from a controlled test environment using US Army airborne radar. A select portion of the experiment will focus on quantifying the aperture integration loss as a function of the horizontal linear feature and various grazing/aspect angles. The findings from both experiments will help identify the total expected loss when different polarizations are used for horizontal linear feature detection.

\section{ACKNOWLEDGMENT}

The authors would like to thank US Army CERDEC I2WD for sponsoring the in-house research effort. The authors would also like to thank the Institute for Defense Analyses (IDA) for their insightful feedback. 


\section{REFERENCES}

[1] M. W. Long, Radar Reflectivity of Land and Sea, Artech House, Norwood, MA, 1983, ch. 3.

[2] F. T. Ulaby and M. C. Dobson, Handbook of Radar Scattering Statistics for Terrain, Artech House, Norwood, MA, 1989, Appendix B pp. 147-165.

[3] C. Wang and W. Yu, Polarimetric calibration requirements for a classification scheme based on scattering type alpha, Geoscience and Remote Sensing Symposium (IGARSS), 2011 IEEE International , pp. 413-415, July 2011.

[4] R. Touzi, W.M. Boerner, J.S. Lee, A review of polarimetry in the context of synthetic aperture radar: concepts and information extraction, Canada Journals on Remote Sensing, vol. 30, no. 3, pp. 380-407, 2004.

[5] R. Touzi, S. Coze, T. Le Toan, A. Lopes, Optimization of Polarimetric Discriminators in SAR Images, Geoscience and Remote Sensing Symposium, 1990 , IGARSS ’90, pp. 1683-1686.

[6] A.A. Schwartz, H.A. Yueh, J.A. Kong, L.M. Novak, R.T. Shin, Optimal polarizations for archiving maximum contrast in radar images, Journal of Geophysical Research, 1988, vol. 93, pp. 15252 - 15260.

[7] G. Zhou, Y. Cui, Y. Chen, J. Yang, H. Rashvand, and Y. Yamaguchi, Linear Feature Detection in Polarimetric SAR Images, IEEE Trans. on Geoscience and Remote Sensing, vol. 49, no. 4, pp. 1453-1463, April 2011.

[8] J. Chanussot, G. Mauris, and P. Lambert, Fuzzy fusion techniques for linear feature detection in multitemporal SAR images, IEEE Trans. on Geoscience and Remote Sensing, vol. 37, no. 3, pp. 1292-1305, May 1999.

[9] A.N. Evans, N.G. Sharp, and E.R. Hancock, Noise models for linear feature detection in SAR images, IEEE Proc. on Image Processing ICIP-94, IEEE International Conference, vol. 1, pp. 466-470, November 1994.

[10] R.C.S. Costa and F.N.S. Medeiros, Linear features detection in SAR images for urban analysis, Proc. on Computer Graphics and Image Processing, pp. 401, 2002.

[11] A. Hendry, J. Skingley, and A.J. Rye, Automated Linear Feature Detection and its Application to Curve Location in Synthetic Aperture Radar Imagery, Geoscience and Remote Sensing Symposium (IGARSS), 1988 IEEE International, vol. 3, pp. 1521-1524, September 1988.

[12] X. Yu, L.E. Hoff, I.S. Reed, A.M. Chen, and D. Buck, A linear feature mapping framework for adaptive detection and recognition of targets in complex SAR data, Signals, Systems and Computers, Asimolar Conference, vol. 1, pp. 127-131, November 1994.

[13] J.S. Lee, D.L. Schuler, T.L. Ainsworth, W.M. Boerner, Polarization orientation estimation and applications: $a$ review, Geoscience and Remote Sensing Symposium (GARSS), vol. 1, pp. 428-430, 2003.

[14] D.A. Hill and M.H. Francis, Out-of-Band Response of Antenna Arrays, IEEE Trans. on Electromagnetic Compatibility, vol. EMC-29, no. 4, pp. 282-288, November 1987.

[15] M. Galletti, D. Zrnic, D. Doviak, Z. Guifu, and J. Crain, Polarimetric phased array weather radar: Concepts for polarimetric calibration, 2010 IEEE International Symposium on Phased Array Systems and Technology (ARRAY), pp. 387-393, October 2010.

[16] A. Maltsev, E. Perahia, R. Maslennikov, A. Sevastyanov, A. Lomayev, and A. Koryaev, Impact of Polarization Characteristics on 60-Hz Indoor Radio Communication Systems, Antennas and Wireless Propagation Letters, vol. 9, pp. 413-416, 2010.

[17] P. Lepsch Mallet de Lima, E.R. Vale, E.E. Vale, Reducing the polarization mismatch for multipath fading systems, 2010 IEEE ANDESCON, pp. 1-6, September 2010.

[18] H.K. Pan, Dual-polarized mm-wave phased array antenna for multi-Gbps $60 \mathrm{GHz}$ communications, 2011 IEEE International Symposium on Antennas and Propagation (APSURSI), pp. 3279-3282, July 2011. 